\title{
Conditional intensity/point process model of task- related prefrontal spiking: effects of performance
}

\author{
David M Devilbiss", Craig W Berridge, Rick L Jenison \\ From Twentieth Annual Computational Neuroscience Meeting: CNS*2011 \\ Stockholm, Sweden. 23-28 July 2011
}

The spiking activity of neurons in the prefrontal associational cortex (PFC) of animals engaged in cognitive tasks is posited to reflect diverse set of independent cognitive and behavioral processes required for the successful attainment of future goals. Additionally, a neural representation of past information (i.e. spike history) is likely critical for performance in these delayed-response tasks of working memory. In the current study, we used a conditional intensity - generalized linear model (CIGLM) statistical framework to determine the degree to which spike history and components of a delayedresponse task predict PFC neural spiking as opposed to traditional peri-event time histogram (PETH) analysis approaches. The final CI-GLM model takes the form, $\lambda\left(t \mid H_{t}\right)=\exp \left\{\mu+\sum_{k=1}^{K} \gamma_{k} \Delta N_{t-k}+\sum_{r=1}^{R} \beta_{r} X_{t}^{r}\right\}$, such that the conditional intensity function $\lambda\left(t \mid H_{t}\right)$ is predicted by a generalized linear model from a series covariates where $(\mu)$ is the intercept of the equation representing

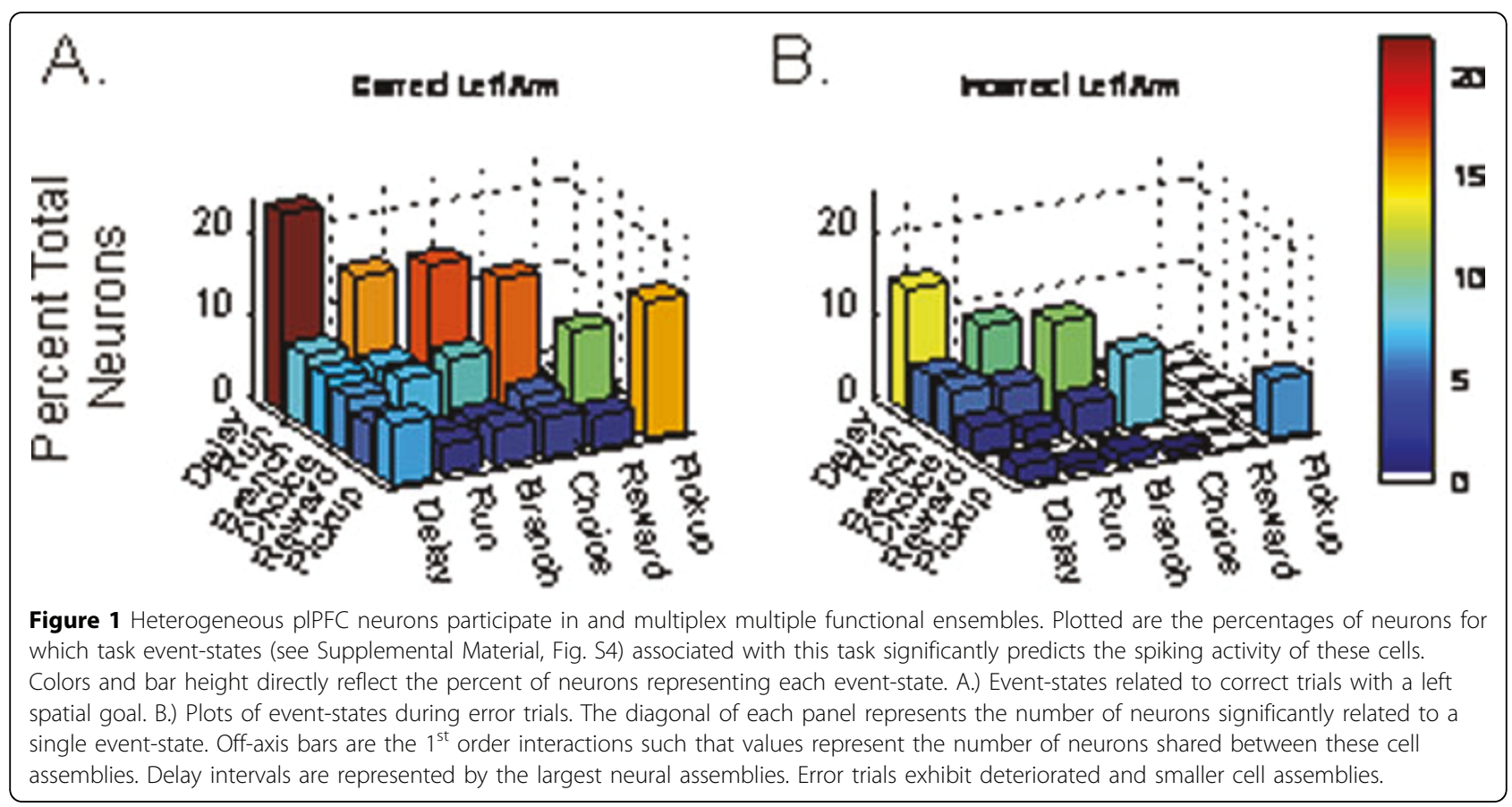

* Correspondence: ddevilbiss@wisc.edu

Psychology Department, University of Wisconsin, Madison, WI 53705, USA 
the background level of activity, $\sum_{k=1}^{K} \gamma_{k} \Delta N_{t-k}$ represents an autoregressive process of order $(K)$, and $\left(X_{t}^{r}\right)$ is the design matrix of each event-state $(r)$ for each sample in time $(t)$ of the behavioral task and $\beta_{r}$ are the estimated weighting parameters. The discretized time for increasing spiking history durations is represented as $\Delta N_{t-k}$ with $\gamma_{k}$ representing the autoregressive coefficients. We found that in rats performing a PFC-dependent delayedalternation task of working memory, the vast majority of PFC neurons participate in the representation of more than one task-related event-state (multiplexer neurons). Additionally, the size of functional neural groups or cell assemblies was critically linked to the level of behavioral performance (Fig. 1). Poor behavioral performance was not solely associated with an attenuation of spiking activity, but instead the activation of inappropriate assemblies during error trials may actively direct the animal towards an incorrect choice. Furthermore, we demonstrate that spike history improves predictions of neural activity within the PFC. In particular, the eventstate most strongly associated with spike history effects was when animals revealed the decision to enter a particular maze arm. Combined, these and other results suggest that PFC spiking activity may reflect an overarching action-plan or policy rather than multiple independent cognitive processes.

Published: 18 July 2011

doi:10.1186/1471-2202-12-S1-P160

Cite this article as: Devilbiss et al:: Conditional intensity/point process model of task-related prefrontal spiking: effects of performance. $B M C$ Neuroscience 2011 12(Suppl 1):P160.

\section{Submit your next manuscript to BioMed Central} and take full advantage of:

- Convenient online submission

- Thorough peer review

- No space constraints or color figure charges

- Immediate publication on acceptance

- Inclusion in PubMed, CAS, Scopus and Google Scholar

- Research which is freely available for redistribution

Submit your manuscript at www.biomedcentral.com/submit
C Biomed Central 